\title{
Obtaining reliable embodied carbon values for geosynthetics
}

\author{
J. Raja ${ }^{1}$, N. Dixon ${ }^{2}$, G. Fowmes ${ }^{3}$, M. Frost ${ }^{4}$ and P. Assinder ${ }^{5}$ \\ ${ }^{1}$ Engineering doctorate student, School of Civil and Building Engineering, Loughborough University, \\ Loughborough, UK, Telephone: +44 (0)7826 545676, Telefax: +44 (0)1509 223981, \\ E-mail: j.raja@lboro.ac.uk \\ ${ }^{2}$ Professor, School of Civil and Building Engineering, Loughborough University, Loughborough, UK, \\ Telephone: +44 (0)1509 228542, Telefax: +44 (0)1509 223981,E-mail: N.Dixon@lboro.ac.uk \\ (corresponding author) \\ ${ }^{3}$ Lecturer, School of Civil and Building Engineering, Loughborough University, Loughborough, UK, \\ Telephone: +44 (0)1509 223775, Telefax: +44 (0)1509 223981,E-mail: G.J.Fowmes@lboro.ac.uk \\ ${ }^{4}$ Senior Lecturer, School of Civil and Building Engineering, Loughborough University, Loughborough, \\ UK, Telephone: +44 (0)1509 228306, Telefax: +44 (0)1509 223981, E-mail: M.W.Frost@lboro.ac.uk \\ ${ }^{5}$ Past Chairman,International Geosynthetics Society: UK Chapter; Area Manager Africa, Huesker \\ Synthetic GmbH, Fabrikstraße 13-15, 48712 Gescher, Germany, Telephone: +44 (0)1746 769537, \\ Telefax:+44(0)1384 379773, E-mail: assinder@HUESKER.com
}

Received 07 January 2015, revised 25 April 2015, accepted 16 May 2015, published 26 August 2015

\begin{abstract}
Changing climate and the damaging effects of carbon dioxide $\left(\mathrm{CO}_{2}\right)$ on the environment, has led to awareness throughout the construction industry of the need to deliver more sustainable solutions. Robust and rigorous carbon footprinting procedures for assessing solutions and projects can help to identify where action can be taken to reduce $\mathrm{CO}_{2}$ emissions. It also promotes the marketing of those solutions and methods that produce lower $\mathrm{CO}_{2}$ emissions. Geosynthetics often provide a costefficient alternative to more 'traditional' construction techniques. Recently, work by the Waste and Resources Action Programme in the UK has shown that geosynthetic solutions can also produce much lower $\mathrm{CO}_{2}$ emissions. However, there are still questions as to the reliability of such calculations. Although the methodologies employed are relatively consistent worldwide, the accuracy of the embodied carbon data available for use in calculations remains uncertain. Geosynthetic products are not specifically included in the embodied carbon construction materials databases most commonly employed in Europe, and often generic values for polypropylene and polyethylene are used. This paper presents a study in which the embodied carbon data for geosynthetic products was calculated using first-hand manufacturing process data. The values calculated for two categories of geosynthetics were considerably lower than commonly employed database values. Nonwoven geotextiles had an average embodied carbon value of $2.35 \mathrm{tCO}_{2} \mathrm{e} / \mathrm{t}$, with values for example geogrids of $2.97 \mathrm{tCO}_{2} \mathrm{e} / \mathrm{t}$ for extruded and $2.36 \mathrm{tCO}_{2} \mathrm{e} / \mathrm{t}$ woven.
\end{abstract}

KEYWORDS: Geosynthetics, Sustainability, $\mathrm{CO}_{2}$, Carbon footprinting, Embodied carbon, Energy

REFERENCE: Raja, J., Dixon, N., Fowmes, G., Frost, M. and Assinder, P. (2015). Obtaining reliable embodied carbon values for geosynthetics. Geosynthetics International, 22, No. 5, 393-401.

[http://dx.doi.org/10.1680/gein.15.00020]

\section{INTRODUCTION}

Global warming and climate change has become a concern worldwide. The increased frequency of extreme weather events and natural disasters has increased awareness among governments and compelled many into taking action. Increased awareness and decisions to take action gained impetus in 1988 when the Intergovernmental Panel on Climate Change (IPCC) was established by the United Nations Environment Programme and World Meteorological Organisation. The IPCC was formed to deliver a global scientific view on the current state of knowledge in climate change and its potential impacts, both environmental and socio-economic (IPCC 2014). International action was further strengthened in 1992 when the United Nations Framework Convention on Climate Change (UNFCCC) was established, which is an international treaty between 195 countries (UN 1992). The UNFCCC encouraged industrialised nations to reduce greenhouse gas (GHG) emissions; leading to the Kyoto Protocol (UN 1998) that set legal emissions commitments on 37 industrialised nations including the UK, other countries in the European Union (EU) and Australia among others.

The main factor attributed to climate change is the rise in greenhouse gases (GHGs; EPA 2014). Although there 
are a number of gases that fall under the banner of GHGs, the biggest single contribution is made by carbon dioxide $\left(\mathrm{CO}_{2}\right)$, which accounts for $76 \%$ of the world's GHG emissions (Ecofys 2013). The influence of $\mathrm{CO}_{2}$ on total GHG emissions has made it the primary target in acting on climate change. One example is the EU who has been actively involved in reducing $\mathrm{CO}_{2}$ emissions and GHGs by introducing the Emissions Trading System (ETS). Launched in 2005 it works as a 'cap and trade' principle limiting the amount of $\mathrm{CO}_{2}$ emissions and GHG produced by energy using installations such as power plants and the manufacturing industry. The EU ETS operates in its 28 member countries, and also includes Iceland, Norway and Lichtenstein, and covers around $45 \%$ of the EU's GHG emissions (EU 2013).

The rising global focus on reducing $\mathrm{CO}_{2}$ emissions over a range of sectors is also impacting on the construction industry. Targets for sustainable low-carbon construction are being set by countries worldwide and as in the case of this study, sustainability is being defined as a means of reducing $\mathrm{CO}_{2}$ emissions. The construction industry's drive for sustainable practices is focused on reducing $\mathrm{CO}_{2}$ because this contributes to national targets for reducing emissions. However, it should be noted that this addresses only one part of the accepted concept of sustainability encompassing environmental, economic and social aspects. The Asian Development Bank (ADB) is an example of a client/investor that is focusing on the issue of reducing $\mathrm{CO}_{2}$ emissions from construction and specifically focused on transport projects (ADB 2010a). The ADB have also taken this a step further and subsequently developed a methodology for carbon footprinting of road projects (ADB 2010b). Similarly, individual nations such as the UK are actively promoting sustainable construction practice, by producing strategies (BERR 2008) and setting up dedicated groups such as the 'Innovation and Growth Team' to meet the low-carbon agenda (IGT 2010).

The growing emphasis on sustainable low-carbon construction has stimulated research and 'green' construction worldwide (McGraw-Hill Construction 2013). Research to date ranges from carbon footprinting of construction projects to the $\mathrm{CO}_{2}$-saving benefits of employing certain solutions and products. One such group of solutions that have shown to provide $\mathrm{CO}_{2}$ savings is the use of geosynthetics. Studies such as those by Waste and Resources Action Programme (WRAP 2010) have demonstrated that geosynthetic solutions provide significant $\mathrm{CO}_{2}$ and cost savings when compared to more traditional construction solutions. The case studies produced by WRAP (2010) covered a range of applications from embankments to reinforced walls. However, the scope was limited to the function of reinforcement and life cycle boundary conditions of cradle to site (see Section 3.2). The European Association of Geosynthetic Manufacturers (EAGM) analysed four case studies (Stucki et al. 2011) to include the functions of reinforcement, drainage and filtration. Geosynthetic and traditional solutions were compared in eight environmental impact categories for life cycle analysis (LCA) boundary conditions of cradle to grave. The impact categories were: cumulative energy demand, climate change (global warming potential), photochemical ozone formation, particulate formation, acidification, eutrophication, land competition and water use. The EAGM case studies not only extended the WRAP work on range of functions and applications but also highlighted the environmental benefits of employing geosynthetics across this range of environmental measures. The WRAP (2010) and Stucki et al. (2011) findings were supported by Heerten (2012) in his study that compared $\mathrm{CO}_{2}$ and cumulative energy demand (CED) between geosynthetic and traditional solutions in road and steep slope applications. In all these studies the calculation of $\mathrm{CO}_{2}$ emissions for construction solutions follow a similar methodology and vary only on the life cycle boundaries and conditions set. However, as the embodied carbon data employed is derived from general database plastic values, there is the possibility of introducing inaccuracies into the calculations, and hence conclusions drawn from these studies.

There is a dearth of geosynthetic-specific embodied carbon data contained within construction material databases across the world and this threatens the credibility of reported $\mathrm{CO}_{2}$ savings possible from the use of geosynthetic-based solutions. The aim of the study reported in this paper was to carry out analysis of embodied carbon values for the manufacture of common categories of geosynthetics. The paper reports the methodology employed in calculating an embodied carbon value for two categories of geosynthetics: geotextiles and geogrids. These categories contain four types of geosynthetics, which were further broken down into products and materials used. The average embodied carbon values calculated for the different types of geosynthetics were compared to values currently included in the commonly used databases.

\section{EMBODIED CARBON DATA FOR GEOSYNTHETICS}

The embodied carbon (EC) of a material can be defined as the amount of $\mathrm{CO}_{2}$ emissions released in the extraction, manufacture and transport of the material. Often in reported EC studies the term embodied energy (EE) is used interchangeably with EC, depending on what form of analysis is being carried out. Embodied energy represents an embodied carbon equivalent value in terms of the energy used in these processes. Primarily, studies calculate EE of a material as this can be easily measured using appropriate energy meters. These EE values can then be converted to EC values using appropriate conversion factors derived from knowledge of the processes used to make the energy (i.e. coal, nuclear, hydro power generation) consumed in the manufacturing process (Defra 2013). Embodied carbon of a material is calculated as tonnes of $\mathrm{CO}_{2}$ per mass of material (e.g. $\mathrm{tCO}_{2} / \mathrm{t}$ ). Where the embodied carbon values are obtained from calculated embodied energy (e.g. see Section 4.2.1), the unit descriptor is $\mathrm{tCO}_{2} \mathrm{e} / \mathrm{t}$.

The representation of an EC value is dependent on which LCA stages are selected. For instance, EC values might represent all the $\mathrm{CO}_{2}$ emissions up until the factory 
gate (cradle to gate) or once the material has reached its end location (cradle to site). An example demonstrating how boundary conditions can be applied is provided by Crishna et al. (2011) in their study of EE and $\mathrm{CO}_{2}$ of dimension stone. The EC data in combination with $\mathrm{CO}_{2}$ emissions from other LCA phases such as construction, maintenance and waste give the overall carbon footprint of a project. However, the inclusion of different phases and activities is dependent on the scope of the study and the LCA boundary conditions set. EC values stated for materials in databases and inventories are often quantified for cradle to gate. The reasoning behind this is that it allows those employing the values to add on projectspecific transport emissions, which are governed by mode of transport and distances, rather than having this included within material embodied carbon values. An example of a database that states all its values as cradle to gate is the Inventory of Carbon and Energy (ICE) database v2.0 (Hammond and Jones 2011).

The ICE database (Hammond and Jones 2011) is one of the most comprehensive sources of EC data for construction materials worldwide. Formed by extracting data from peer-reviewed literature, the ICE database lists EE and EC information for over 200 different materials that are commonly used in the construction industry (Hammond and Jones 2008a). It has been employed in a variety of embodied carbon studies including work by Hughes et al. (2011) on earthworks and Zhang et al. (2011) on a typical bridge deck replacement. The ICE database has also become the primary source of data for a range of construction carbon footprinting tools, such as the one developed by the Environment Agency for England and Wales (EA 2012). An alternative to the ICE database is a European life cycle analysis database called 'EcoInvent v3.0' (EIC 2013). Unlike the ICE database, which specifically focuses on the EE/EC of materials, the EcoInvent database provides data for a wide range of life cycle indicators. As reported in Section 1, this range of indicators was used in the life cycle assessments performed in the EAGM study (Stucki et al. 2011).

The EcoInvent and ICE databases both provide embodied carbon values for plastics that are used in the manufacture of geosynthetics and these reported values are comparable. This similarity is due to both databases obtaining values through review of the same sources of literature such as the work carried out by Boustead (2005) for PlasticsEurope. However, there are differences between the databases in the form and description of the material data. Table 1 presents data from both ICE databases v2.0 and v1.6 and provides corresponding data from EcoInvent v2.2 (EIC 2010). It should be noted that the EcoInvent v2.2 and v3.0 values for plastics are unchanged as they are obtained from the same literature (e.g. Boustead 2005). Based on the material descriptions in the ICE database the EcoInvent data is only able to provide comparative values for a subset of the materials listed. There are also differences between the two ICE versions, with the materials listed in Table 1 having higher embodied carbon values in the latest dataset (v2.0) than in the earlier version (v1.6). The variation in embodied
Table 1. Embodied carbon values for different plastics from ICE (Hammond and Jones 2008b, 2011) and EcoInvent v2.2 (EIC 2010)

\begin{tabular}{|l|c|c|l|}
\hline \multirow{2}{*}{ Material } & \multicolumn{3}{|c|}{ Embodied carbon $\left(\mathrm{kg} \mathrm{CO}_{2} \mathrm{e} / \mathrm{kg}\right)$} \\
\cline { 2 - 4 } & $\begin{array}{c}\text { ICE v2.0, } \\
2011\end{array}$ & $\begin{array}{c}\text { ICE v1.6a, } \\
2008\end{array}$ & $\begin{array}{l}\text { EcoInvent } \\
\text { v2.2, 2010 }\end{array}$ \\
\hline General plastic & 3.31 & 2.53 & - \\
$\begin{array}{l}\text { General polyethylene } \\
\text { High-density }\end{array}$ & 2.54 & 1.94 & - \\
$\quad$ polyethylene (HDPE) & 1.93 & 1.60 & 1.91 \\
HDPE pipe & 2.52 & 2.00 & - \\
$\begin{array}{l}\text { Low-density } \\
\text { polyethylene (LDPE) }\end{array}$ & 2.08 & 1.70 & 2.06 \\
$\begin{array}{l}\text { LDPE film } \\
\text { Polypropylene, }\end{array}$ & 2.60 & 1.90 & 2.66 \\
$\quad$ orientated film & 3.43 & 2.70 & - \\
$\begin{array}{l}\text { Polypropylene, injection } \\
\text { moulding }\end{array}$ & 4.49 & 3.90 & - \\
$\begin{array}{l}\text { Polypropylene, granules } \\
\text { Polyester, granules }\end{array}$ & - & - & 1.98 \\
$\begin{array}{l}\text { Polyester, granules - } \\
\text { bottle grade }\end{array}$ & - & - & 2.70 \\
\hline
\end{tabular}

carbon data for materials can be attributed to a number of factors such as different boundary conditions, manufacturing differences and product specifications (Menzies et al. 2007). The values provided have not accounted for variances in finished product and instead an average EC value for specific materials such as high-density polyethylene (HDPE) is reported. The assumptions and generalised categorisation of the materials presented in these commonly used databases leads to uncertainty with regards to the relevance and validity of this published data when used for geosynthetic products.

As geosynthetic products have no specific representation in the ICE or EcoInvent databases, the values do not account for product-specific information obtained from the manufacturing process. An example would be sourcing a value for a polypropylene (PP)-based geotextile from the ICE database. It can be seen from Table 1 that there are two possible alternatives values for PP. However, neither of these specifically represents a geotextile. It is arguable that the manufacturing processes included in the calculation of embodied carbon for orientated film or injection moulded products are not applicable for a geotextile. Use of these generic values for a PP geotextile in a carbon footprinting analysis of a construction solution may give incorrect and inconsistent results. This degree of variability and uncertainty could lead to challenges to the validity of such calculations from those outside the geosynthetic industry, especially when analyses show the geosynthetic solution to be more sustainable.

\section{METHOD FOR CALCULATING EMBODIED CARBON VALUES}

\subsection{Introduction}

The process of calculating an embodied carbon value for a geosynthetic product relies on energy measurements as 
well as embodied data for the materials. This study focused on two categories of geosynthetics: geotextiles and geogrids. Data for several products of two different types of both geotextiles and geogrids were sourced to produce embodied carbon values for each type and category. In order to effectively carry out the study, energy consumption was measured on the production lines used to manufacture the products. The energy consumed is then converted to the total $\mathrm{CO}_{2}$ produced by applying the relevant factors based on the fuel mix employed. Co-operation of the manufacturers was required to source the relevant data with four global operating manufacturers contributing to this study. The participating manufacturers provided energy readings and data for product manufacturing lines, and material masses where a range of products have been studied. This produced data covering a range of commonly used geosynthetic products.

\subsection{Life cycle boundaries}

In order to calculate a complete EC value, all the phases of the life cycle have to be considered up until the product leaves the factory gate; adhering to the life cycle boundaries of cradle to gate. Presenting the values to these boundary conditions allows the outputs of this study to be compared to the ICE and EcoInvent database values. It also facilitates the use of the values in studies calculating carbon footprints of construction solutions incorporating geosynthetics. For example, if a study is using life cycle boundaries of cradle to site, emissions from transport of the material to site can be added to the product-embodied carbon value in order to meet the life cycle boundary conditions. Figure 1 illustrates the different life cycle boundary conditions related to the manufacture and use of geosynthetics.

As this study worked to LCA boundaries of cradle to gate, alongside the $\mathrm{EC}$ data for the material and the process-related $\mathrm{CO}_{2}$ emissions there was the need to consider emissions related to transport of materials to

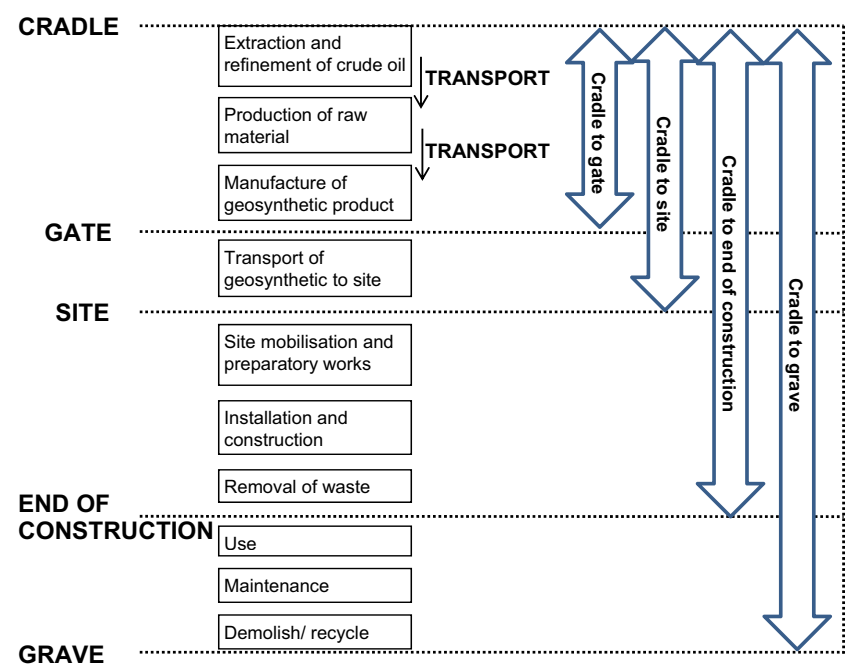

Figure 1. Life cycle boundaries employed in $\mathrm{CO}_{2}$ analysis of geosynthetics the manufacturing plant. The EC values of polymer pellets are stated as cradle to gate, and hence already account for any transport $\mathrm{CO}_{2}$ emissions up to the time when the pellets are ready to leave the original factory gate. However, there is a need to account for the $\mathrm{CO}_{2}$ emissions that arise from the transport of the polymer pellets from the manufacturer to the geosynthetic product manufacturer. This transport phase is dependent on a manufacturer's capabilities. For instance, one of the geotextile manufacturers in this study used polymer pellets directly in their process to manufacture staple fibres, whereas another used polymer pre-processed into staple fibres by a supplier directly in their manufacturing process (see Section 3.3). Therefore, additional transport from the staple fibre manufacturer to the geosynthetic manufacturer had to be considered in the second example.

\subsection{Procedure for measurements}

Prior to carrying out any measurements of energy used in the manufacture of specific products it was important to identify the embodied carbon of the raw material being used. In the case of the geotextiles and the extruded geogrid this was PP. The EcoInvent database provides a cradle to gate embodied carbon value for PP granules (EIC 2010) and therefore it was not necessary to replicate this calculation for the raw material (Table 1). This value was then combined with the amount of carbon produced in the manufacture of the geosynthetic products (e.g. geotextiles and extruded geogrids; Table 2) to give an overall value. Similar steps are followed for the woven geogrid, which employs polyester as the raw material.

Four geosynthetic manufacturers contributed to this study; two provided data on the production of nonwoven geotextiles, one on extruded geogrids and another on woven geogrids (Table 2). In the case of the geotextiles, each manufacturer employed a different manufacturing process. The geotextiles from manufacturer A were needle-punched, whereas manufacturer B predominately used thermal bonding, although production lines could employ a mixture of both methods. As previously discussed manufacturer A had the polypropylene delivered as staple fibre bales and manufacturer B did this conversion in-house requiring measurement of the energy consumed buy this phase of the manufacturing process. Energy usage was measured using a, Socomec Countis E50 electrical energy meter, with an accuracy of $0.5 \%$, at the supply source of the manufacturing line. On completion of a batch of staple fibres, the amount of energy consumed per kilogram of material produced was calculated. This measurement procedure was repeated for products with a range of masses per unit area in order to provide data for a variety of commonly used products. The amount of energy consumed was then converted to a carbon dioxide equivalent (Equation 1) using conversion factors presented by the UK Department for Environment, Food and Rural Affairs (Defra 2013).

A similar methodology was employed to calculate the embodied carbon for the extruded and woven geogrids but full details of the energy measurements for the manufacturing process were not available for publication in this 
Table 2. $\mathrm{CO}_{2}$ emissions from manufacturing phase (note: the breakdown of carbon emission values from manufacturers $\mathrm{C}$ and $\mathrm{D}$ are not available)

\begin{tabular}{|c|c|c|c|c|c|c|c|}
\hline \multirow[t]{2}{*}{ Manufacturer } & \multirow[t]{2}{*}{ Type } & \multirow[t]{2}{*}{ Product } & \multirow[t]{2}{*}{ Material } & \multirow[t]{2}{*}{$\operatorname{Mass}\left(\mathrm{kg} / \mathrm{m}^{2}\right)$} & \multicolumn{2}{|l|}{ Energy (electricity) } & \multirow{2}{*}{$\begin{array}{l}\text { Carbon } \\
\text { emissions } \\
\left(\mathrm{tCO}_{2} \mathrm{e} / \mathrm{t}\right)\end{array}$} \\
\hline & & & & & $(\mathrm{kWh} / \mathrm{t})$ & $\left(\mathrm{kWh} / \mathrm{m}^{2}\right)$ & \\
\hline A & $\begin{array}{l}\text { Nonwoven geotextile } \\
\text { (needle-punched) }\end{array}$ & $\begin{array}{l}1 \\
2 \\
3 \\
4 \\
5 \\
6\end{array}$ & $\begin{array}{l}\text { PP } \\
\text { PP } \\
\text { PP } \\
\text { PP } \\
\text { PP } \\
\text { PP }\end{array}$ & $\begin{array}{l}0.371 \\
0.366 \\
0.539 \\
0.642 \\
1.120 \\
1.233\end{array}$ & $\begin{array}{l}144.689 \\
143.155 \\
109.966 \\
107.422 \\
101.343 \\
110.110\end{array}$ & & $\begin{array}{l}0.064 \\
0.064 \\
0.049 \\
0.048 \\
0.045 \\
0.049\end{array}$ \\
\hline B & $\begin{array}{l}\text { Nonwoven geotextile } \\
\text { (thermally bonded/ } \\
\text { needle-punched) }\end{array}$ & $\begin{array}{l}- \\
1 \\
2\end{array}$ & $\begin{array}{l}- \\
\text { PP } \\
\text { PP }\end{array}$ & $\begin{array}{l}- \\
0.07-0.15 \\
0.135-1.2\end{array}$ & $\begin{array}{l}\text { Electricity }(\mathrm{kWh} / \mathrm{t}) \\
222 \\
240\end{array}$ & $\begin{array}{l}\text { Gas }(\mathrm{kWh} / \mathrm{t}) \\
620 \\
315\end{array}$ & $\begin{array}{l}- \\
0.213 \\
0.165\end{array}$ \\
\hline $\mathrm{C}$ & Geogrid (extruded) & $\begin{array}{l}1 \\
2 \\
3\end{array}$ & $\begin{array}{l}\mathrm{PP} \\
\mathrm{PP} \\
\mathrm{PP}\end{array}$ & $\begin{array}{l}0.232 \\
0.290 \\
0.320\end{array}$ & $\begin{array}{l}- \\
- \\
-\end{array}$ & $\begin{array}{l}- \\
- \\
-\end{array}$ & $\begin{array}{l}- \\
- \\
-\end{array}$ \\
\hline $\mathrm{D}$ & Geogrid (woven) & 1 & PET & 0.530 & - & - & - \\
\hline
\end{tabular}

PET, polyester; PP, polypropylene.

paper, therefore they are not reported separately in Table 2. Manufacturers $\mathrm{C}$ and D carried out all the necessary energy measurements and life cycle calculations in house and provided an average embodied carbon value for categories of geosynthetics (see Table 5 below). These include all processes involved in the manufacturing process (e.g. surface treatments). The authors reviewed the calculations to ensure a consistent methodology was employed to that used for the geotextiles and outlined above.

\section{CALCULATED EMBODIED CARBON VALUES}

\subsection{Transport $\mathrm{CO}_{2}$ emissions}

The transport $\mathrm{CO}_{2}$ emissions of the materials (Figure 1) were calculated based on a methodology employed in previous carbon footprinting studies such as those by Raja et al. (2014a) and WRAP (2010). This was only applicable to the geotextiles as the embodied carbon values sourced for the geogrids from manufacturers $\mathrm{C}$ and D already accounted for such transport-related emissions. A road transport mechanism (20 t rigid heavy goods vehicle (HGV)) was assumed with a fuel consumption of $3.33 \mathrm{~km} / 1$ (DfT 2012). This, a $\mathrm{CO}_{2}$ emissions value for diesel of $2.60 \mathrm{kgCO}_{2}$ per litre of fuel (Defra 2013) and actual material transport distances were employed in Equation 1. The results presented in Table 3 demonstrate that the transport of the PP material produces very little in terms of $\mathrm{CO}_{2}$ emissions when compared with the embodied carbon of the material itself.

$$
C=\frac{\beta(2 \mathrm{D} / \alpha)}{1000 Q}
$$

where $C$ is the total $\mathrm{CO}_{2}$ emissions per tonne $\left(\mathrm{tCO}_{2} / \mathrm{t}\right), D$ is the distance of transportation $(\mathrm{km}), Q$ is the quantity of material (tonnes), $\alpha$ is the fuel consumption of the rigid $\mathrm{HGV}$ and $\beta$ is the $\mathrm{CO}_{2}$ emissions per litre of fuel.

\subsection{Manufacturing process $\mathrm{CO}_{2}$ emissions}

\subsubsection{Relating embodied energy and embodied carbon}

Results were obtained for the four types of geosynthetics: two types of geotextiles and two types of geogrids. Each manufacturer was able to provide data for a range of products that covered varying masses and production results. This allowed the overall energy consumption per kilogram of product produced to be calculated (Table 2). In order to present these results in the form of EC, the energy consumed had to be converted to EC values using appropriate $\mathrm{CO}_{2}$ emissions factors. This was achieved by combining the energy readings with the conversion factors for electricity of $0.44548 \mathrm{kgCO}_{2} \mathrm{e} / \mathrm{kWh}$ and gas $0.18404 \mathrm{kgCO}_{2} \mathrm{e} / \mathrm{kWh}$ (Defra 2013) in Equation 2. These conversion factors are based on UK energy values and represent the direct emissions at the point of use of the fuel or generation of electricity. They do not account for indirect emissions associated with factors such as extraction of the gas; setting up of a power plant and so on. The factors are susceptible to change and can vary worldwide. For instance a country employing more renewable energy sources would subsequently produce less $\mathrm{CO}_{2}$ per unit of energy.

$$
E \times \alpha=C
$$

where $E$ is the energy consumed $(\mathrm{kWh} / \mathrm{t}), \alpha$ is the conversion factor $\left(\mathrm{tCO}_{2} / \mathrm{kWh}\right)$ and $C$ is the embodied carbon $\left(\mathrm{tCO}_{2}\right)$.

\subsubsection{Geotextiles}

Manufacturers A and B provided data for a range of geotextile products with varying mass per unit area. The manufacturing energy measurements were recorded for each roll of product produced and repeated numerous 
Table 3. $\mathrm{CO}_{2}$ emissions for transport of PP materials for geotextile manufacture

\begin{tabular}{|c|c|c|c|c|c|}
\hline Manufacturer & Material & Transport phases & $\begin{array}{l}\text { Cumulative transport } \\
\text { distances }(\mathrm{km})\end{array}$ & $\begin{array}{c}\text { Fuel } \\
\text { consumed } \\
\text { (litres) }\end{array}$ & $\begin{array}{c}\text { Total } \mathrm{CO}_{2} \\
\left(\mathrm{tCO}_{2} / \mathrm{t}\right)\end{array}$ \\
\hline A & PP & $\begin{array}{l}\text { - PP pellets to fibre manufacturer } \\
\text { - PP fibres to geosynthetic manufacturer }\end{array}$ & 94.1 & 56.5 & 0.007 \\
\hline B & PP & - PP pellets to geosynthetic manufacturer & 56 & 34 & 0.004 \\
\hline
\end{tabular}

times in order to account for any variability in the manufacturing process.

Table 2 includes the $\mathrm{CO}_{2}$ emissions generated from the conversion of the fibres to a finished geotextile for both manufacturers. The process to produce the staple fibres involves the extrusion, spinning and stretching of granules to create fibres and then cutting and pressing of the fibres to create bales. Manufacturer B carried out all these processes on site using a mix of different energy supplies; electric and gas. The data provided by manufacturer $\mathrm{B}$ allowed an average carbon emissions value for this phase to be calculated (Table 4). The same energy mix was assumed for the geotextile production as used in the conversion of the fibres by manufacturer $\mathrm{B}$. This value combined with the averaged manufacturing process emissions (Table 2) and the raw material embodied carbon gave an overall embodied carbon value for the nonwoven geotextiles from each manufacturer (Table 5). The values in Table 5 also include all material-related transport emissions that are required to fulfil the LCA criteria of cradle to gate. Although the values for transport-related $\mathrm{CO}_{2}$ emissions are small (Table 3) compared to the embodied and manufacturing emissions they have been included to maintain consistency in the study. The average mass per unit area for each type of manufactured geosynthetic is reported in Table 2. The results suggest

Table 4. Carbon emissions for conversion of polypropylene granules to staple fibres (manufacturer B)

\begin{tabular}{|l|l|c|c|}
\hline Energy source & $\begin{array}{l}\text { Consumption } \\
(\mathrm{kWh} / \mathrm{t})\end{array}$ & $\begin{array}{c}\text { Carbon } \\
\text { emissions } \\
\left(\mathrm{tCO}_{2} / \mathrm{t}\right)\end{array}$ & $\begin{array}{c}\text { Total } \\
\left(\mathrm{tCO}_{2} / \mathrm{t}\right)\end{array}$ \\
\hline Electricity & 450 & 0.200 & 0.241 \\
Gas & 222 & 0.041 & \\
\hline
\end{tabular}

that for geotextiles with a larger mass per unit area, less energy is consumed when measured per tonne of geotextile produced.

The total embodied carbon values calculated for the geotextiles provided by the two manufacturers are very similar with only a $5 \%$ difference. This small difference arises in the manufacturing process and is primarily due to differences in energy sources employed. Manufacturer A relies solely on grid electricity, whereas manufacturer B also uses natural gas. However, machine and process efficiencies will also contribute to the difference in $\mathrm{CO}_{2}$ emissions. The total embodied carbon for the products produced by manufacturers A and B can be averaged to give a representative value for nonwoven geotextiles of $2.35 \mathrm{tCO}_{2} \mathrm{e} / \mathrm{t}$ for cradle to gate.

\subsubsection{Geogrids}

Manufacturers C and D carried out the measurement independently providing an overall embodied carbon value for their products, which were calculated to life cycle boundary conditions of cradle to gate (Figure 1). This meant a carbon emissions value specific to the manufacturing process was not available for publication, although as noted in Section 3.3 a review of the methodologies they used showed them to be comparable with this study. Manufacturer $\mathrm{C}$ provided values for three different masses per unit area of geogrid. The raw material embodied carbon value of polypropylene (Table 1) was the same as used for the geotextiles and was sourced from data contained in the EcoInvent database (EIC 2010). Manufacturer D presented data for one geogrid product formed from polyester. For the geogrids, the overall EC values calculated and supplied by the manufacturer account for the raw material-embodied carbon, its transport to the manufacturing plant and the carbon emissions from the manufacturing process.

Table 5. Overall embodied carbon for each product

\begin{tabular}{|l|l|c|c|c|c|}
\hline Manufacturer & Type & $\begin{array}{c}\text { PP embodied } \\
\text { carbon }\left(\mathrm{tCO}_{2} \mathrm{e} / \mathrm{t}\right)\end{array}$ & $\begin{array}{c}\text { Granules to fibre } \\
\left(\mathrm{tCO}_{2} \mathrm{e} / \mathrm{t}\right)\end{array}$ & $\begin{array}{c}\text { Average manufacturing carbon } \\
\text { emissions }\left(\mathrm{tCO}_{2} \mathrm{e} / \mathrm{t}\right)\end{array}$ & $\begin{array}{c}\text { Total embodied } \\
\text { carbon }\left(\mathrm{tCO} \mathrm{O}_{2} / \mathrm{t}\right)\end{array}$ \\
$\mathrm{A}$ & $\begin{array}{c}\text { Nonwoven geotextile } \\
\text { (needle-punched) } \\
\text { Nonwoven geotextile } \\
\text { (thermally bonded/ } \\
\text { needle-punched) } \\
\text { Geogrid (extruded) } \\
\text { Geogrid (woven) }\end{array}$ & 1.983 & 0.241 & 0.053 & 2.28 \\
$\mathrm{C}$ & - & - & 0.189 & 2.42 \\
$\mathrm{D}$ & - & - & - & 2.987 \\
\hline
\end{tabular}


The extruded geogrid had an EC of $2.97 \mathrm{tCO}_{2} \mathrm{e} / \mathrm{t}$ and the woven geogrid $2.36 \mathrm{tCO}_{2} \mathrm{e} / \mathrm{t}$. Unlike the geotextiles which were formed from the same material the geogrids varied both in manufacturing processes and raw materials employed. Hence a difference between the embodied carbon values of the two geogrids was expected. As for the geotextiles, variances in energy sources employed and machine efficiencies will also contribute to the differences.

\subsubsection{Summary of manufacturing $\mathrm{CO}_{2}$ emissions}

The results from both categories of geosynthetics highlight that the biggest contribution to the overall embodied carbon of each product is made by the embodied carbon of the raw material. However, the manufacturing process still accounts for a considerable amount of the overall embodied carbon of up to $33 \%$.

\section{COMPARISON OF GEOSYNTHETIC-SPECIFIC AND DATABASE VALUES}

The aim of this study was to calculate embodied carbon values for categories and types of geosynthetics. Currently, the commonly used databases do not provide geosynthetic-specific values and hence there is a degree of ambiguity and uncertainty regarding the accuracy of carbon footprinting of projects including geosynthetics. Table 6 presents a comparison of the geosynthetic EC values calculated in this study with the generic values currently available from databases; both are for cradle to gate LCA boundaries. The comparison shows that values calculated in this study have significant differences to the database values. In the case of geosynthetics manufactured from PP, the ICE database values commonly employed can be up to $90 \%$ higher than those calculated in this study for a PP-based geotextile or geogrid. Therefore, the use of these database values in carbon footprinting studies will overestimate calculated emissions. EcoInvent Centre (EIC 2010) only present data for PP in granulate form, which does not represent the embodied carbon of a finished product.

A similar trend was obtained for the polyester-based geogrid. The EcoInvent database in this instance presents values for polyester (granulate) in two different forms (Table 1). Although the values are for granulate and not a finished material they are still higher than the value calculated for the polyester woven geogrid by manufacturer D. The ICE database does not have any specific values for polyester; however, values for general plastics and polyethylene have previously been used as alternatives (WRAP 2010). These values for general plastics and polyethylene are all higher than that calculated for the woven geogrid. Thus using any of these alternative material-embodied carbon values to represent polyester-based geogrids would overestimate the total $\mathrm{CO}_{2}$ of the geosynthetic-based solution.

It is important to note that this study does not suggest the database values are inaccurate as the values stated are not direct comparisons. They are values for different forms of materials whether it be granulate or in the case of polypropylene, injection moulding or orientated film. Due to a lack of specific embodied carbon values for geosynthetics, these values have commonly been employed as alternatives for geosynthetic products. However, the values reported in this paper can now be used for future carbon footprinting, to provide more rigorous construction solution assessments.

\section{SIGNIFICANCE OF MATERIAL-EMBODIED CARBON ON PROJECT CARBON FOOTPRINTING}

The importance of using accurate EC data for geosynthetics can be demonstrated by re-working of case studies reported by WRAP (2010) and Raja et al. (2014b) using specific EC values for geotextile and geogrids calculated in this study. WRAP (2010) detail a case study from the Commonhead Junction Improvement project in Swindon, UK. The case study focused on the construction of an embankment for a dual two-lane flyover and compared the cost and $\mathrm{CO}_{2}$ emissions of geosynthetic base and more established solutions. The geosynthetic solution involved the use of a geogrid to reinforce site-won material as compared to the originally proposed solution that required the import of granular material. The polyester geogrid employed accounted for $30.56 \mathrm{tCO}_{2}$, which is just less than $10 \%$ of the overall emissions for the solution. The embodied carbon data was sourced from the ICE database v1.6 (Hammond and Jones 2008b), which has no stated value for polyester and uses a value for general polyethylene of $1.94 \mathrm{tCO}_{2} \mathrm{e} / \mathrm{t}$ (Table 1). This ICE v1.6 value is lower than the value calculated for a polyester geogrid of $2.36 \mathrm{tCO}_{2} \mathrm{e} / \mathrm{t}$ (Table 5) and therefore the revised project $\mathrm{CO}_{2}$ savings calculated are lower than those originally

Table 6. Comparison of calculated embodied carbon values with commonly employed database values for cradle to gate LCA boundaries

\begin{tabular}{|l|l|l|l|l|}
\hline & \multicolumn{2}{|l|}{ Calculated EC values $\left(\mathrm{tCO}_{2} \mathrm{e} / \mathrm{t}\right)$} & \multicolumn{2}{l|}{ Database EC values $\left(\mathrm{tCO}_{2} \mathrm{e} / \mathrm{t}\right)$} \\
\hline \multirow{2}{*}{ Polypropylene } & Nonwoven geotextile (average) & Extruded geogrid & ICE v2.0 & EcoInvent v2.2 \\
& 2.35 & 2.97 & 3.43 to 4.49 & 1.98 \\
Polyester & Woven geogrid & & ICE v2.0 & EcoInvent v2.2 \\
& 2.36 & 2.54 to 3.31 & 2.70 to 2.90 \\
\hline
\end{tabular}

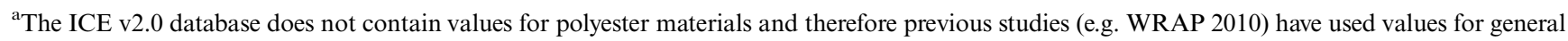
polyethylene and plastics (general) as alternatives. 
calculated. The impact of employing the geosyntheticspecific calculated value increases the $\mathrm{CO}_{2}$ emissions to $37.21 \mathrm{tCO}_{2}$, an increase of $22 \%$ for this case study.

Raja et al. (2014b) present a case study that compared the carbon dioxide emissions produced from a compacted clay landfill cap with a solution incorporating polypropylene-based geosynthetics. The lifecycle analysis boundaries set for the case study were cradle to end-of-construction. As-built data provided by contractors and manufacturers were used to calculate the carbon footprint of each solution and the comparison showed the geosynthetic solution produced less $\mathrm{CO}_{2}$ emissions. The use of a database EC value of $3.43 \mathrm{tCO} 2 \mathrm{e} / \mathrm{t}$ for the polypropylene-based geotextiles overestimated the total $\mathrm{CO}_{2}$ emissions when compared with the value obtained using the calculated average geotextile $\mathrm{EC}$ value of 2.35 $\mathrm{tCO}_{2} \mathrm{e} / \mathrm{t}$. The Raja et al. (2014b) case study overestimated the $\mathrm{CO}_{2}$ emissions from the embodied carbon of the geotextiles by $45 \%$.

These examples provide motivation for carrying out further studies of the type reported in this paper to obtain specific embodied carbon values for other geosynthetic products. The availability of such data will increase the accuracy of carbon footprinting of construction solutions incorporating geosynthetic products. It will also reduce the opportunity for challenges to the validity and accuracy of comparisons between geosynthetic solutions and those employing other construction materials and approaches.

\section{CONCLUSIONS}

There is a lack of geosynthetic-specific embodied carbon data in the literature for use in construction project carbon footprinting calculations. The use of generic material values obtained from commonly used databases can have significant impact on the accuracy of carbon footprinting results. The study reported in this paper was carried out to calculate the embodied carbon values for two categories of geosynthetics subdivided into four types: nonwoven geotextile needle-punched; nonwoven geotextile needlepunched and thermally bonded; extruded geogrid; and woven geogrid. The geosynthetic-type-specific values calculated were lower than the commonly employed ICE and EcoInvent database values.

The paper reports embodied carbon values for geotextiles and geogrids to the life cycle boundary conditions of cradle to gate. The methodology involved making energy measurements during production, converting these to embodied carbon values, and combining these with embodied carbon data for the raw materials and any transport associated emissions. In the case of the geotextiles, energy measurements for converting polypropylene granules through to manufacture of the end product were obtained from various production lines operated by two manufacturers. A similar methodology was employed for the geogrids, however this was carried out by the geogrid manufacturers themselves. The overall energy consumed in producing a tonne of each geotextile or geogrid was then converted to a $\mathrm{CO}_{2}$ equivalent using appropriate energy to carbon conversion factors set out by Defra (2013).

The results from the two geotextile manufacturers were very similar with only a $5 \%$ difference. The geotextile from manufacturer A had an embodied carbon of $2.28 \mathrm{tCO}_{2} \mathrm{e} / \mathrm{t}$ in comparison with $2.42 \mathrm{tCO}_{2} \mathrm{e} / \mathrm{t}$ from manufacturer B. The difference in values can be attributed to different manufacturing processes and fuel sources. Manufacturer $\mathrm{B}$ used a combination of electricity and gas and employed both needle-punching and thermal bonding techniques, compared with manufacturer A who used electricity and needle punching. The mean value for nonwoven geotextiles was $2.35 \mathrm{tCO}_{2} \mathrm{e} / \mathrm{t}$. Results for two types of geogrids were also obtained, namely $2.97 \mathrm{tCO}_{2} \mathrm{e} / \mathrm{t}$ for the extruded geogrid and $2.36 \mathrm{tCO}_{2} \mathrm{e} / \mathrm{t}$ for the woven geogrid. The difference between the two geogrids is thought to be due to differences in the raw materials and manufacturing processes employed.

With no specific embodied carbon values available for geosynthetics until this study, WRAP (2010) and Raja et al. (2014a, 2014b) used database values. In instances where polypropylene-based nonwoven geotextiles or geogrids are being employed, the value for polypropylene (orientated film) from the ICE database is commonly used. This ICE database value of $3.43 \mathrm{tCO}_{2} \mathrm{e} / \mathrm{t}$ is $46 \%$ higher than that of $2.35 \mathrm{tCO}_{2} \mathrm{e} / \mathrm{t}$ calculated for the geotextiles and $15 \%$ higher than the $2.97 \mathrm{tCO}_{2} \mathrm{e} / \mathrm{t}$ of the geogrid. There are also instances where the lack of specific embodied carbon data has led to values of alternative materials of similar properties being employed. In the absence of information for polyester, WRAP (2010) used a value for general polyethylene.

This study highlights the importance of and need for geosynthetic-specific embodied carbon values. The use of these values in construction project $\mathrm{CO}_{2}$ calculations will aid accuracy and hence credibility to project carbon footprinting results. This will further highlight the sustainability benefits, in terms of reduced embodied carbon, of geosynthetic-based solutions while also minimising doubts or challenges that may exist with regard to the basis for the embodied carbon values employed. The publication of embodied carbon data for an extensive range of geosynthetics would allow clients and consultants to undertake their own robust calculations. This study has provided embodied carbon values for two different categories of geosynthetics. However, there is a need to develop, add and extend this dataset to a range of other categories of geosynthetics. Geosynthetic manufacturers are encouraged to extend the findings of this study to include data for their own products. The availability of comprehensive data would allow production of a geosynthetics-embodied carbon inventory and extension of existing databases to include geosynthetics.

\section{ACKNOWLEDGEMENTS}

This paper was completed as part of an engineering doctorate project being carried out at the Centre for Innovative and Collaborative Construction Engineering 
(CICE), Loughborough University. The authors would like to acknowledge the International Geosynthetics Society (UK Chapter), the corporate sponsors who provided data, CICE, Loughborough University and the Engineering and Physical Sciences Research Council, who funded this project.

\section{REFERENCES}

ADB (Asian Development Bank) (2010a). EKB: REG 2010-16: Reducing Carbon Emissions from Transport Projects, Independent Evaluation Department, Asian Development Bank, Manila, Philippines.

ADB (2010b). Methodology for Estimating Carbon Footprint of Road Projects - Case Study: India, Asian Development Bank, Manila, Philippines.

BERR (Department for Business, Enterprise and Regulatory Reform) (2008). HM Government Strategy for Sustainable Construction, Department for Business, Enterprise and Regulatory Reform, HM Government, London, UK.

Boustead, I. (2005). Eco-profiles of the European Plastics Industry, Association of Plastics Manufacturers in Europe (PlasticsEurope), Brussels, Belgium.

Crishna, N., Banfill, P. F. G. \& Goodsir, S. (2011). Embodied energy and $\mathrm{CO}_{2}$ in UK dimension stone. Resources, Conservation and Recycling, 55, No. 12, 1265-1273.

Defra (Department for Environment, Food and Rural Affairs) (2013). Guidelines to Defra's GHG Conversion Factors for Company Reporting, Department for Environment, Food and Rural Affairs, London, UK.

DfT (Department for Transport) (2012). Domestic Road Freight Activity (RFS01) - Table RFS0141: Fuel Consumption by HGV Vehicle Type in Great Britain, 1993 to 2010, Department for Transport, London, UK. See https://www.gov.uk/government/statistical-datasets/rfs01-goods-lifted-and-distance-hauled (accessed 12/08/2015).

EA (Environment Agency) (2012). Environment Agency Construction Carbon Calculator, Environment Agency, Bristol, UK. See https:// www.gov.uk/government/organisations/environment-agency/about/ procurement (accessed 12/08/2015).

Ecofys (2013). World GHG Emissions Flow Chart 2010. Ecofys, London, UK. See http://www.ecofys.com/files/files/asn-ecofys-2013-worldghg-emissions-flow-chart-2010.pdf (accessed 25/11/2014).

EIC (EcoInvent Centre) (2010). EcoInvent Data v2.2, Ecoinvent reports No. 1-25. Swiss Centre for Life Cycle Inventories, Duebendorf, Switzerland.

EIC (2013). EcoInvent Data v3.0, Ecoinvent reports No. 1-25. Swiss Centre for Life Cycle Inventories, Duebendorf, Switzerland.

EPA (US Environmental Protection Agency) (2014). Causes of Climate Change, United States Environmental Protection Agency, Washington, DC, USA. See http:/www.epa.gov/climatechange/ science/causes.html (accessed on 21/11/2014).

EU (European Union) (2013). The EU Emissions Trading System (EU ETS). European Union Publications Office, Brussels, Belgium. [http://dx.doi.org/10.2834/55480]
Hammond, G. P. \& Jones, C. I. (2008a). Embodied energy and carbon in construction materials. Proceedings of the Institution of Civil Engineers - Energy, 161, No. 2, 87-98.

Hammond, G. P. \& Jones, C. I. (2008b). Inventory of (Embodied) Carbon \& Energy (ICE). Department of Mechanical Engineering, University of Bath, Bath, UK.

Hammond, G. P. \& Jones, C. I. (2011). Inventory of (Embodied) Carbon \& Energy (ICE) v2.0. Department of Mechanical Engineering, University of Bath, Bath, UK.

Heerten, G. (2012). Reduction of climate-damaging gases in geotechnical engineering practice using geosynthetics. Geotextiles and Geomembranes, 30, 43-49.

Hughes, L., Phear, A., Nicholson, D., Pantelidou, H., Soga, K., Guthrie, P., Kidd, A. \& Fraser, N. (2011). Carbon dioxide from earthworks: a bottom-up approach. Proceedings of the Institution of Civil Engineers - Civil Engineering, 164, No. 2, 66-72.

IGT (Innovation and Growth Team) (2010). Low Carbon Construction Innovation and Growth Team: Final Report, Report Number: BIS/11/10/NP. Department for Business, Innovation and Skills, London, UK.

IPCC (Intergovernmental Panel on Climate Change) (2014). Organization. Intergovernmental Panel on Climate Change, Geneva, Switzerland. See http://www.ipcc.ch/organization/organization. shtml (accessed 05/12/2014).

McGraw-Hill Construction (2013). Smart Market Report: World Green Building Trends, McGraw-Hill Construction, New York, NY, USA.

Menzies, G. F., Turan, S. \& Banfill, P. F. G. (2007). Life-cycle assessment and embodied energy: a review. Proceedings of the Institution of Civil Engineers - Construction Materials, 160, No. 4, 135-143.

Raja, J., Dixon, N., Fowmes, G., Frost, M. \& Assinder, P. (2014a). The sustainable use of geosynthetics: landfill drainage case study. Proceedings of 10ICG, Berlin, Germany, 21-25 September 2014, Paper No. 113.

Raja, J., Dixon, N., Fowmes, G., Frost, M. \& Assinder, P. (2014b). Comparison of carbon dioxide emissions for two landfill capping layers. Proceedings of the Institution of Civil Engineers Engineering Sustainability, 167, No. 5, 197-207.

Stucki, M., Büsser, S., Itten, R., Frischknecht, R. \& Wallbaum, H. (2011). Comparative Life Cycle Assessment of Geosynthetics Versus Conventional Construction Materials, report for the European Association of Geosynthetic Manufacturers, ESU-services $\mathrm{GmbH}$, Uster, Switzerland and ETH Zürich, Switzerland.

UN (United Nations) (1992). United Nations Framework Convention On Climate Change. S. Treaty Doc No. 102-38, 1771 U.N.T.S. 107. United Nations, New York, NY, USA.

UN (1998). Kyoto Protocol to the United Nations Framework Convention on Climate Change. U.N. Doc FCCC/CP/1997/7/ Add.1, 37 I.L.M. 22. United Nations, New York, NY, USA.

WRAP (Waste and Resources Action Programme) (2010). Sustainable Geosystems in Civil Engineering Applications, Project MRF116. Waste and Resources Action Programme, Banbury, UK.

Zhang, C., Amaduddin, M. \& Canning, L. (2011). Carbon dioxide evaluation in a typical bridge deck replacement project. Proceedings of the Institution of Civil Engineers - Energy, 164, No. 4, 183-194.

The Editor welcomes discussion on all papers published in Geosynthetics International. Please email your contribution to discussion@geosynthetics-international.com by 15 April 2016. 